\title{
Anabases
}

ANABASES Traditions et réceptions de l'Antiquité

$20 \mid 2014$

Varia

\section{Jason KÖNIG, Aikaterini OIKONOMOPOULOU et Greg \\ Woolf (éd.), Ancient Libraries}

\section{Mathilde Cambron-Goulet}

\section{OpenEdition}

Journals

Édition électronique

URL : http://journals.openedition.org/anabases/5186

DOI : $10.4000 /$ anabases. 5186

ISSN : 2256-9421

Éditeur

E.R.A.S.M.E.

\section{Édition imprimée}

Date de publication : 1 novembre 2014

Pagination : 421-423

ISSN : 1774-4296

\section{Référence électronique}

Mathilde Cambron-Goulet, « Jason кönIG, Aikaterini oıкоnomopoulou et Greg Woolf (éd.), Ancient Libraries », Anabases [En ligne], 20 | 2014, mis en ligne le 01 novembre 2014, consulté le 22 septembre 2020. URL : http://journals.openedition.org/anabases/5186; DOI : https://doi.org/10.4000/anabases.5186

Ce document a été généré automatiquement le 22 septembre 2020

(c) Anabases 


\title{
Jason KÖNIG, Aikaterini OIKONOMOPOULOU et Greg WOOLF (éd.), Ancient Libraries
}

\author{
Mathilde Cambron-Goulet
}

\section{RÉFÉRENCE}

Jason KöNIG, Aikaterini oIKONOMOPoulou et Greg Woolf (éd.), Ancient Libraries,

Cambridge-New York, Cambridge University Press, 2013, 479 p.

75 livres / ISBN 9781107012561

1 Ancient Libraries avait pour objectif d'offrir une synthèse des connaissances sur les bibliothèques de l'Antiquité à partir de sources variées. Comme le souligne Woolf, les historiens se heurtent à deux difficultés: la rareté des témoignages sur les bibliothèques antiques qui les amène à répéter les récits des historiens antiques, et la projection sur les bibliothèques antiques de diverses pratiques modernes : l'ouverture des bibliothèques au public, les objets qui y étaient conservés, les contextes de production de savoirs, les pratiques de lecture ou encore l'identité des lecteurs. Les études qui composent Ancient libraries montrent les rapports qu'entretiennent les bibliothèques avec les littératures, l'histoire du livre, les savoirs, ainsi que les activités de recherche scientifique qu'elles facilitent. Les articles se rencontrent sur plusieurs plans, aussi je soulignerai les thèmes qui émergent du volume collectif sans suivre le parcours chronologique qu'ont privilégié les éditeurs.

Quelques contributions remettent en question des lieux communs sur les bibliothèques hellénistiques. Ryholt recherche les origines de la bibliothèque d'Alexandrie dans la culture savante égyptienne - plutôt que grecque - en étudiant la bibliothèque du temple de Tebtunis. Les chercheurs sur les religions antiques liront, en parallèle, la contribution d'Affleck, qui étudie la préhistoire des bibliothèques romaines à partir des collections de livres et du rôle de l'écrit dans la religion romaine évoqués par la 
tradition littéraire, et établit une distinction entre archives et bibliothèques qui trouve écho dans l'article de Robson. Handis montre la construction du mythe de la bibliothèque d'Alexandrie dans l'Antiquité, chaque récit prêtant à ce lieu des collections plus importantes que le précédent, tandis que Hatzimichali s'attaque au mythe de la destruction de la bibliothèque d'Alexandrie, qui selon elle ne fut que partielle, de sorte que bien qu'ayant perdu son prestige, la bibliothèque a continué à être un centre intellectuel significatif après 48 av. J.-C. Coqueugniot nous invite quant à elle à remettre en question l'identification et la reconstitution de la bibliothèque de Pergame, qui apparaît dès lors comme une institution privée de bâtiment.

3 L'ouvrage nous éclaire aussi sur la nature des bibliothèques antiques. Robson remarque que la distinction qu'établissent les assyriologues entre bibliothèques et archives est parfois délicate dans la mesure où la composition et la fonction des bibliothèques cunéiformes varient suivant les contextes socio-politiques et les thèmes de prédilection des copistes et auteurs qui les remplissent, d'autant plus que ces bibliothèques n'ont pas de fonction publique. Jacob propose une relecture des sources qui permet de distinguer les bibliothèques, caractérisées par leur organisation, des simples collections de livres - un point de vue qu'il partage avec Martinez et Senseney qui montrent comment cette différence s'opère dans les bibliothèques spécialisées, qu'elles soient publiques et privées, puisque les lecteurs s'en servent de manière complémentaire. Deux études de cas illustrent la manière dont se constituent les collections privées dans l'Antiquité, soit l'article de Houston sur la diversité des provenances, mains d'écriture, contenus et annotations des manuscrits de la Villa des Papyrus d'Herculanum, et l'article de Dix qui étudie les transformations de la bibliothèque de Cicéron à l'aide des récits d'achats, de cadeaux, d'héritages et de pertes de livres que l'on trouve dans sa correspondance. La contribution de Hogg évoque cette dynamique entre les collections de livres privées et publiques, en montrant que le premier livre des Antiquités romaines, publié séparément, était destiné à une large diffusion dans les collections privées internationales, alors que les livres subséquents étaient destinés aux bibliothèques publiques, de sorte que le lectorat du premier livre était plus étendu. Les études de Pinto et Harder, qui examinent respectivement la manière dont la circulation des livres transforme le travail intellectuel dans l'Athènes classique, et l'impact des ressources de la bibliothèque sur l'utilisation des sources chez Callimaque et Apollonios, éclairent le fonctionnement des bibliothèques publiques et la notion de publication antique.

4 Le dernier thème qui ressort de l'ouvrage est le rapport entre l'espace savant et l'espace public. Zadorojnyi, qui compare la conception des bibliothèques chez Galien et Plutarque, montre que si le premier déplore qu'elles ne garantissent pas l'authenticité des œuvres - remarque grâce à laquelle Galien met en valeur son sens critique comme chercheur -, le second les voit surtout comme des lieux de sociabilité savante. De fait, la culture de lecture dans laquelle les bibliothèques s'inscrivent est une culture de partage et de sociabilité organisée autour d'un grand personnage, comme le souligne Johnson qui base une partie de son analyse sur un passage de Galien. Tutrone étudie l'influence des réseaux intellectuels et sociaux sur le fonctionnement des bibliothèques privées comme lieux culturels, puisqu'elles sont des lieux d'échange et de rencontre, où les livres sont recopiés, vendus et achetés. Les articles de Nicholls et de Tucci gagnent à être lus de concert : le premier, en notant que les espaces communs des bibliothèques sont, d'un point de vue architectural, mis en valeur, montre que les bibliothèques publiques romaines sont des lieux d'affaires publiques, tandis que le second, en reconstituant les bibliothèques flaviennes à partir de traces archéologiques et 
littéraires, discute autant de la qualité de leurs collections respectives et de l'espace de rangement disponible que des lieux exacts où se rassemblaient les chercheurs. On note enfin la dimension politique de la culture savante: Bowie nous renseigne sur la manière dont les bibliothécaires romains étaient choisis par les empereurs entre le $\mathrm{I}^{\mathrm{er}} \mathrm{s}$. av. J.-C. et le II ${ }^{\mathrm{e}}$ s. ap. J.-C. ; Neudecker compare les bibliothèques aux espaces votifs dans les sanctuaires, puisqu'elles fonctionnent comme lieux de représentation du pouvoir par le biais des œuvres incluses - ou non - dans la collection, et par l'accessibilité restreinte ou étendue des ouvrages; Petrain montre que, comme la construction de bâtiments spécifiquement destinés à accueillir des bibliothèques, l'utilisation d'armoria destinés à ranger les papyri tout en les mettant en valeur à l'aide des portraits des auteurs est une innovation romaine, et une expérience visuelle ayant pour effet l'affirmation d'un pouvoir.

5 Les lecteurs les mieux servis, à mon sens, seront ceux qui s'intéressent aux bibliothèques comme lieux de sociabilité, et ceux qui se préoccupent de la conception des bibliothèques dans l'œuvre de Galien - pas moins de quatre contributions lui sont consacrées -, mais les éditeurs, en privilégiant des contributions qui se croisent et se répondent sans jamais se répéter, montrent que les lieux de savoir antiques gagnent à être étudiés à partir d'une diversité de points de vue.

\section{AUTEURS}

\section{MATHILDE CAMBRON-GOULET}

Université du Québec à Montréal

cambron-goulet.mathilde@uqam.ca 